\title{
WestVirginiaUniversity
}

THE RESEARCH REPOSITORY @ WVU

Graduate Theses, Dissertations, and Problem Reports

2007

\section{Dialectical tensions in stroke survivor relationships}

Kimberly N. Leezer

West Virginia University

Follow this and additional works at: https://researchrepository.wvu.edu/etd

\section{Recommended Citation}

Leezer, Kimberly N., "Dialectical tensions in stroke survivor relationships" (2007). Graduate Theses,

Dissertations, and Problem Reports. 4314.

https://researchrepository.wvu.edu/etd/4314

This Thesis is protected by copyright and/or related rights. It has been brought to you by the The Research Repository @ WVU with permission from the rights-holder(s). You are free to use this Thesis in any way that is permitted by the copyright and related rights legislation that applies to your use. For other uses you must obtain permission from the rights-holder(s) directly, unless additional rights are indicated by a Creative Commons license in the record and/ or on the work itself. This Thesis has been accepted for inclusion in WVU Graduate Theses, Dissertations, and Problem Reports collection by an authorized administrator of The Research Repository @ WVU. For more information, please contact researchrepository@mail.wvu.edu. 
Dialectical Tensions in Stroke Survivor Relationships

\author{
Kimberly N. Leezer \\ Thesis submitted to the \\ Eberly College of Arts and Sciences \\ at West Virginia University \\ in partial fulfillment of the requirements \\ for the degree of \\ Master of Arts \\ in \\ Communication Theory and Research \\ Maria Brann, Ph.D., Chair \\ Megan Dillow, Ph.D. \\ Keith Weber, Ed.D. \\ Department of Communication Studies \\ Morgantown, West Virginia
2007
}

Keywords: Dialectical Tensions, Stroke, Spouse, Relationship 


\section{ABSTRACT \\ Dialectical Tensions in Stroke Survivor Relationships \\ Kimberly N. Leezer}

Stroke is an unpredictable and life-altering medical occurrence which causes immediate change in stroke survivors' relationships. Previous communication researchers have focused on the dialectical tensions experienced by stroke survivors themselves. This study sought to discover dialectical tensions experienced by spouses of stroke survivors, how those dialectical tensions compare to those experienced by stroke survivors, and how time affects the dialectical tensions experienced by spouses of stroke survivors. Sixteen spouses of stroke survivors participated in interviews, and five tensions were ultimately discovered: self-preference - partner-preference, realism - idealism, freedomconstraint, fear - content, and emotional release - emotional reservation. Three dialectical tensions (i.e., fear - content, realism - idealism, freedom - constraint) were similar to those experienced by stroke survivors, and time affected three dialectical tensions (i.e., realism - idealism, fear - content, freedom - constraint). Implications of these findings and directions for future research are discussed. 


\section{DEDICATION}

In memory of Mary Jo "Nanny" Leezer, a wonderful woman and grandmother, who was the inspiration for this study. You influenced my life in countless ways and are greatly missed.

In honor of Harry Burl "Pop" Swisher, a brilliant man and wonderful grandfather, who's determination and strength are inspirational not only for this study, but for life. You hold a special place in my heart.

In honor of all the participants and their spouses. Everyone I met and spoke with was amazing. I never could have done this without you. Thank you.

I would like to thank God for blessing me with intelligence, for the opportunity to use and increase it, for wonderful family and friends to support me, and for the strength to endure whatever obstacles come my way.

Thanks to my advisor, Dr. Brann, for all of her assistance, advice, understanding, and encouragement during this process. I never could have done this without her.

Thanks to Maverick Brann for all of his help and for being patient and understanding during meetings.

Thanks to my committee members for their advice and help with this study. Your feedback and help are greatly appreciated.

Thanks to Sylvia, Jennifer, and Lisa. Without your help and enthusiasm I never could have completed this project. Thank you for everything.

Thank you to Michael Himes. If it weren't for you, I never would have made it through this. Thank you for being my alarm clock during all-nighters, my editor, my biggest critic, and my strongest supporter. Thanks for making me smile when everything seemed dismal, for reminding me to pause and have some fun from time to time, and for putting up me with when I was stressed. I am more grateful than words can say for everything you have done for me; you are the love of my life (we'll see about penciling your name in on my degree).

Thank you to my mother, Pamela. You are an amazing and inspirational woman. Thank you for the sacrifices you have made in your life and career so that I could have opportunities and a role model. You taught me to give my all both academically and in life, to follow my dreams, and that I can do anything I put my mind to. You are my hero and I hope that I can follow your lead and be the type of mother and woman you are. I love you.

Thank you to my father, Bob. I never could have imagined or wished for a better father. Thank you for the sacrifices you have made to make my life better and for the valuable 
lessons you have taught me (I didn't let it win). Thank you for teaching me to laugh, not only at myself, but at situations that otherwise might seem hopeless. You are my hero and I love you.

Thank you to my sister, Kristen. Your study habits and determination are amazing and an inspiration. I have always admired them, attempted to learn from them, and can only wish to equal them. I love you.

Thank you to my brother, Matthew. You are an encouragement and have always been there to make me work harder. You make me push myself to achieve at your level and I have often found myself surprised at where I ended up. I love you.

Thanks to the Benn's (Jennifer, Jerry, Devyn, and Jillian) for letting me stop by and unwind. You were often a port in the storm and spending even just a moment with you made my day better (a game or a bit of Barney or Dora before media studies was a nice break).

Thanks to my fellow Master's students. It has been an interesting year and you all will always hold a special place in my heart and memory. It was the best of times, it was the worst of times, and sometimes it seemed like the end of times, but we always made it through. Thanks for listening to my rants. I can't believe we actually made it.

Thanks to all of the inspirational teachers who made learning fun and taught me how to prevail even when it wasn't. Mrs. English, Mr. Reed, Mr. Wolfter, Mrs. Hawkins, Ms. Plachta, Dr. "Doc" Curtis, Dr. Oppe, and Dr. Long, who all laid a foundation and built upon it so that I could achieve my dreams. Thanks to them and may others.

Thanks to all of my family and friends who believed in me and supported me. My life would be empty and boring without you. I love you. 
TABLE OF CONTENTS

Page

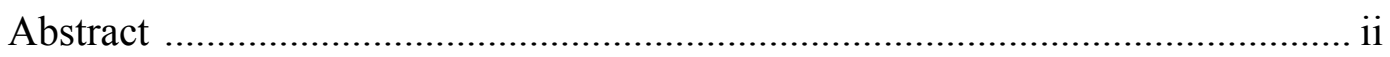

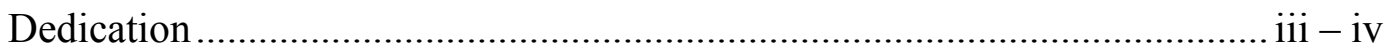

Table of Contents .................................................................................... vi

I. STATEMENT OF THE PROBLEM.................................................................................1

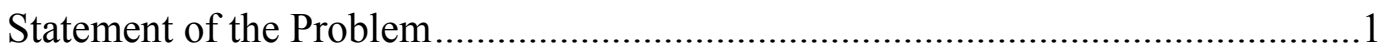

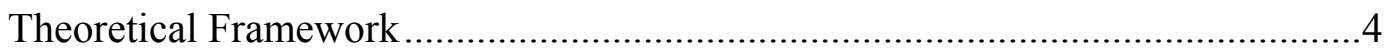

Dialectical Tensions Experienced in Unique Relational Contexts ...........................6

Dialectical Tensions Experienced by Stroke Survivors.........................................9

Dialectical Tensions Experienced by Spouses of Stroke Survivors .......................11

II. METHODOLOGY …........................................................................................................14

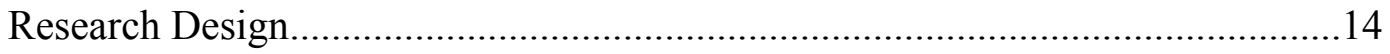

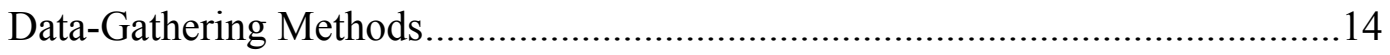

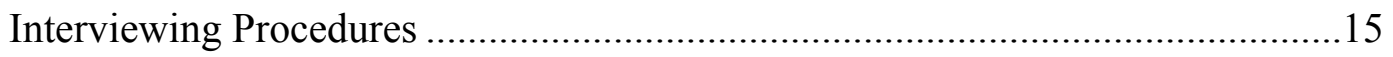

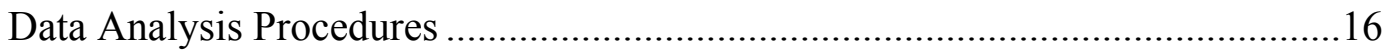

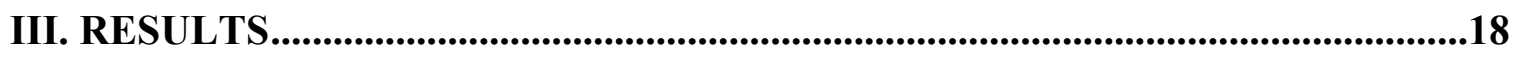

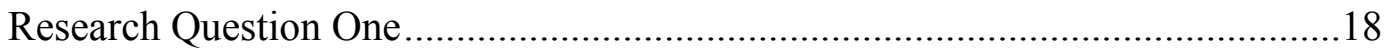

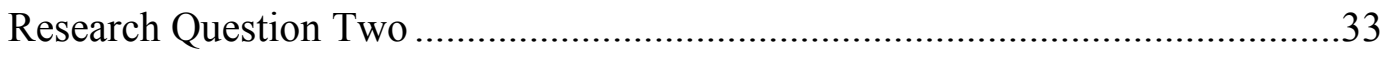

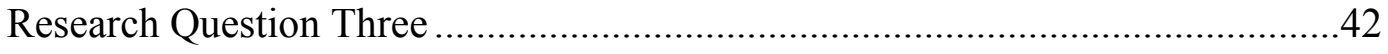

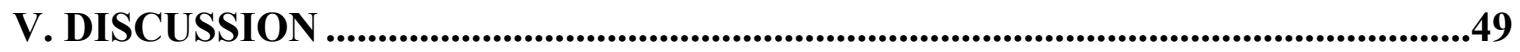

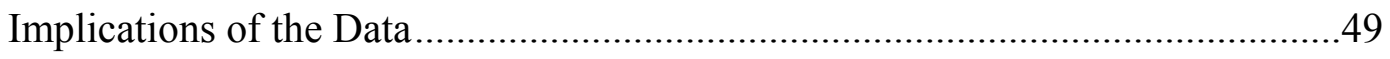

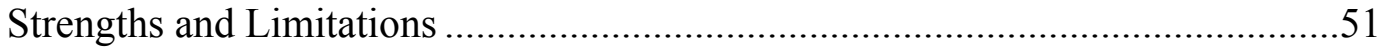


Directions for Future Research.....

Conclusion

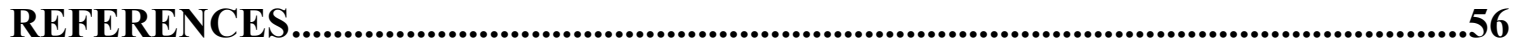

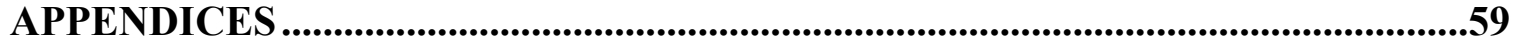

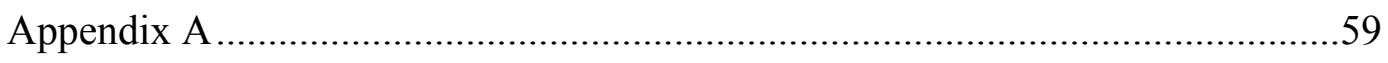

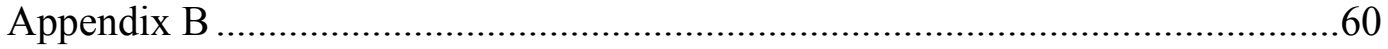

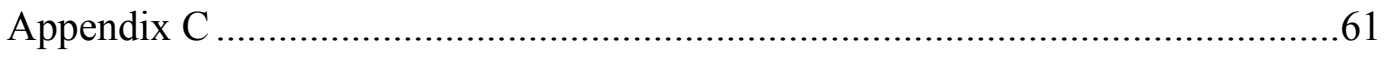

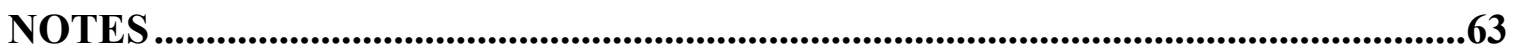

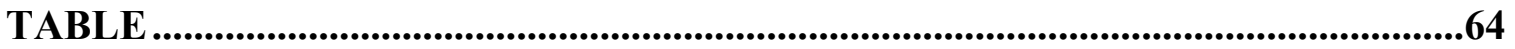

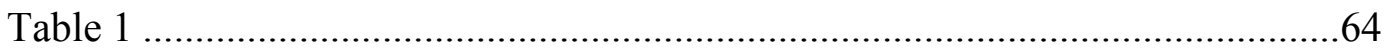




\section{Dialectical Tensions in Stroke Survivor Relationships}

\section{CHAPTER 1}

A stroke occurs approximately every 45 seconds in the United States ("Impact of stroke," n.d.). In fact, more than 600,000 new and recurrent strokes occur in the United States each year (Senlick \& Dougherty, 2001). It is the third most common cause of death and a leading cause for long-term adult disability resulting in one in 10 families being affected by stroke (Senelick \& Dougherty, 2001). The physical and cognitive effects of a stroke can be devastating for a stroke survivor and include: paralysis, vision problems, memory loss, muscle control problems, and speech/language problems ("What are the effects of stroke?" n.d.). These consequences of stroke affect not only the life of the stroke survivor, but also the spouse and family members who must adapt to the resulting changes in their relationship with the survivor. One area where changes occur in the relationship involves the dialectical tensions, the interplay between two opposite feelings/emotions (Baxter \& Montgomery, 1996), with which each member of the relationship must cope.

\section{Statement of the Problem}

According to Palmer, Glass, Palmer, Loo, and Wegener (2004), stroke has dual effects; not only does it change the life of the stroke survivor physically and emotionally, it also affects the stroke survivor's family. Consequently, Palmer notes that these changes produce the need for the medical system to provide the stroke survivor and her/his family with adequate information to adjust to the abrupt changes caused by the stroke. This call for further information for stroke survivors and their families is also applicable to the communication studies field because the abrupt changes caused by the stroke also affect 
relational communication and the structure of the relationship by impinging on normal roles and causing emotional distress (Senelick \& Dougherty, 2001). Numerous studies published in medical journals have examined the relational effects of stroke on the individual and the nurse/caregiver, the spouse (who is also sometimes the caregiver post hospitalization), and the family from a treatment-focused point of view but not a communication studies point of view (e.g., Bluvol \& Ford-Gilboe 2004; Brereton, 1997; Brereton \& Nolan, 2000, 2002; Galarneau, 1993). These studies, although not focused on specific aspects of communication, exemplify the importance of communication and the effects of stroke. For example, Brereton (1997) asserts that stroke, unlike other medical conditions, is sudden, often unexpected, and causes drastic changes in the survivor's status and identity which require them to rely on others to undertake the roles they once held (e.g., a spouse overseeing the family finances, where prior to the stroke, the stroke survivor was responsible). By taking on new roles and attempting to manage a new and unfamiliar situation, stroke survivors and their spouses need to communicate their needs and questions clearly, while constructing understanding of how each is feeling regarding care/recovery and the level of satisfaction/quality of the relationships. Brereton (1997) focuses on the stress the uncertainty and changes resulting from stroke causes the spouse and/or family and how the medical community (i.e., doctors, nurses, other medical professionals) needs to help stroke survivors' and their spouses and families adjust to the changes they are experiencing related to the stroke. Consequently, by better understanding what spouses of stroke survivors are experiencing emotionally and communicatively within their relationship with the stroke survivor, communication research could result in reduced stress for stroke survivors, their spouses, and their 
families.

In addition to reduced stress, Bluvol and Ford-Gilboe (2004) examined hope and quality of life in stroke survivors. The emotional, physical, and psychological effects of stroke impact the entire family. This results in decreased quality of life due to constraint caused by the inability to participate in social events and other activities that were enjoyed prior to the stroke. Bluvol and Ford-Gilboe's (2004) research suggests that a stroke survivor's level of hope (i.e., the ability to find and secure resources which aid in recovery or the acceptance of limitations regarding recovery and devising methods to adapt), in combination with the spouse's level of hope, correlates positively with the couple's quality of life. Moreover, the researchers discovered that despite disabilities caused by the stroke, those couples who were more hopeful perceived their quality of life to be higher (Bluvol \& Ford-Gilboe, 2004). In addition, Senelick and Dougherty (2001) state:

Stroke survivor and family are linked - by their grief, their attitudes, and their pressures. Their reactions might be different, their emotions might feed on each other, but every family member must work together to shape effective strategies for change - and create a healthy home. (p. 183)

Thus, two conclusions can be drawn: a positive outlook combined with communicating positive feelings, both verbally and nonverbally, is beneficial for both members of the relationship, and the spouse's attitude can have an impact on the stroke survivor. Consequently, by understanding what dialectical tensions stroke survivors and their spouses encounter and providing them with an idea of what others in their situation typically experience, such information may help them recognize dialectical tensions they 
have not previously dealt with and realize their feelings are normal. This may enable them to reduce their uncertainty regarding their emotional state and therefore reduce their stress and increase their quality of life.

Moreover, according to research by Santos, Farrajota, Castro-Caldas, and De Sousa (1999), who examined stroke-induced aphasia:

evaluation and treatment [of the stroke survivor] are usually centered on the communication deficit and other aspects of physical distress and are seldom addressed to the individual experience of coping with impairment and to the quality of life, both of the patients and their families. (p. 24)

This oversight is a paramount concern because the research suggests that the attitudes of the stroke survivor and the individuals they have relationships with, particularly spouses and relatives, have great influence on the survivor's well-being and vice versa (Santos et al., 1999; Senelick \& Dougherty, 2001; Bluvol \& Ford-Gilboe, 2004). Consequently, in an effort to increase the quality of life for both stroke survivors and their spouses, in addition to overall health and recovery, there is a need for more research dealing specifically with the relationships and changes in relationships of stroke survivors and their spouses.

\section{Theoretical Framework}

Relational Dialectics Theory (RDT), developed by Baxter and Montgomery (1996), suggests that relational life is characterized by contradictory desires regarding ongoing dialectical tensions (Turner, 2003). The use of the word "contradictory," which normally carries a negative connotation, does not take on such negativity when discussed from the dialectical perspective. Rather, Baxter and Montgomery (1996) define 
contradictions as "the dynamic interplay between unified oppositions" (p. 8) and suggest "contradictions are inherent in social life and not evidence of inadequacy in a person or in a social system" (p. 7). Furthermore, dialectical elements simultaneously work together and against one another resulting in continuous fluctuation along a continuum that exists between the two contradicting emotions reflecting the constant change inherent in relational life (Harvey \& Wenzel, 2001). RDT consists of four basic assumptions regarding relational life: (a) "relationships are not linear," (b) "relational life is characterized by change," (c) "contradiction is the fundamental fact of relational life," and (d) "communication is central to organizing and negotiating relational contradictions" (Turner, 2003, p. 29).

The first and second assumptions suggest that relationships are not an "either/or" situation but rather "both/and" situations. Relationships which are considered to be progressing/changing (i.e., moving in a forward direction and gaining "more") are perceived on a linear path which include more "certain elements such as intimacy, selfdisclosure, certainty, and so forth than relationships that do not progress" (e.g., either intimate or not intimate) (Turner, 2003, p. 29). In response to this common perception of relationships as linear, Baxter and Montgomery (1996) suggest the idea that cyclical change in relationships is a more appropriate description rather than the unidirectional implications of the term linear. The third assumption of RDT differs from most other relational theories; whereas most relational theories view stability as desirable, RDT considers it "unnatural" as change is a normal feature of relational life (Turner, 2003). The fourth assumption was based on three central dialectics: autonomy-connection, openness-closedness, and novelty-predictability (Baxter, 1990), and the reliance on 
communication to manage these contradictions. Baxter and Montgomery (1996) cite individuals' comments during interviews, such as a man who states that when he spends time away from his partner he actually feels closer to her, to provide evidence that managing these dialectical tensions is helpful and vital to a relationship. In addition to looking at heterosexual romantic relationships, broader research has focused on other types of relationships and other dialectical tensions, which are dependent on the type of and the differing components of a relationship.

\section{Dialectical Tensions Experienced in Unique Relational Contexts}

In addition to the studies by Baxter and Montgomery (1996), dialectical tensions have been studied in a variety of other relational contexts. Sabourin and Stamp (1995) examined dialectical tensions in abusive versus nonabusive families and found seven dialectical tensions which emerged unique to abusive family situations. These dialectical tensions include "vague - precise language," "opposition - collaboration," "relational content talk," "despair - optimism," "interfering - facilitating interdependence," "complaints - compliments," and "ineffective - effective change." "Vague - precise language" is defined as the amount of detail individuals provide when discussing a given topic. Sabourin and Stamp (1995) found that individuals in abusive families employ more vague language than those in nonabusive families. The dialectical tension of "opposition - collaboration," involves the level of cooperation within the relationship. Sabourin and Stamp (1995) found that abusive families tended to work against and oppose one another while nonabusive families were more collaborative and tried to work with one another. "Relational - content talk" involves the flow of conversation and staying focused on the content being discussed. Individuals in abusive families deviate from content talk and 
begin to focus on relational talk (i.e., the problems in the relationship) where as individuals in nonabusive families stay focused on content talk even if the discussion could lend itself to relational talk. The "despair-optimism" dialectical tension emerges in regard to the individuals' attitudes toward other family members when discussing their current living situation. Abusive families exhibit more despair in regard to their relationships voicing frustration and anger while nonabusive families are more optimistic and express positive feelings such as joy and contentment. "Interfering - facilitating interdependence" is a dialectical tension which emerges in regard to the level of involvement and influence members of the family have on one another. Abusive families were more likely to complain and voice disapproval with other family members, thus "interfering" and thereby distancing themselves from the family and reducing interdependence. Nonabusive families facilitated interdependence by asking questions and clarifying the needs of other family members as a means of meeting those needs. The "complaints - compliments" dialectical tension involves the communicative behaviors of complaining or complimenting family members. Individuals in abusive families were more likely to complain about other family members, and nonabusive families were more likely to compliment each other and speak to other family members in a positive manner. Finally, Sabourin and Stamp (1995) recognized "ineffective - effective change" as a dialectical tension in abusive versus nonabusive families. This tension involves how change is viewed within the family. Abusive families often discussed areas of contempt which needed change but did not discuss how such change could occur or be achieved. Individuals in nonabusive families discussed change in a manner which suggested they felt in control of their relational situation and appropriate changes could be made when 
needed.

In addition to the context studied by Sabourin and Stamp (1995), Alemán (2001) examined complaining in the elderly as a method for voicing concerns regarding oppositions to independence in retirement community living and found three dialectical tensions emerge: "independence - social constraint" (i.e., desire to make decisions independently but being bound by institution policy), "independence-dependence" (i.e., desire to perform tasks without help but realizing age and condition necessitate help from others and adapting to the need to rely on others), and "independence - interdependence" (i.e., individuals wanting to maintain an independent sense of self despite assisted living condition while still wanting to feel as though they are part of and involved in the community).

Further, Baxter and Erbert (1999) studied the effect of dialectical tensions on turning points in the development of heterosexual romantic relationships. Baxter and Erbert (1999) found two of the original dialectical tensions, "autonomy - connection" and "openness - closedness," were of the greatest importance for the 50 heterosexual romantic couples participating in the study. However, they also found other dialectical tensions that were important during turning points in the relationships: "inclusion seclusion," "revelation - concealment," "predictability - novelty," and "conventionality uniqueness."

Overall, the study of dialectical tensions in unique relational contexts suggests that with each unique situation there are unique dialectical tensions that emerge. Each of the situations discussed previously causes unique changes in relationships and, as exemplified in the study by Sabourin and Stamp (1995), affect how those involved in the 
relationship communicate with one another. In addition to those unique relational contexts discussed above, Pawlowski (2006) examined dialectical tensions in stroke survivors and discovered they too experience unique dialectical tensions.

\section{Dialectical Tensions Experienced by Stroke Survivors}

Pawlowski (2006) partially fulfilled the need for more information regarding stroke survivors and how stroke affects families by conducting research regarding the dialectical tensions experienced between the stroke survivor and caregiver/spouse poststroke. After conducting interviews with stroke survivors, Pawlowski (2006) discovered seven dialectical tensions stoke survivors encounter during daily functioning and communication with their caregiver/spouse: "success/determination - wanting to give up," "isolated/loneliness - support," "fear - content," "independent - dependent," “openness - closedness," "thankfulness - frustration/anger," and "reflections of past/reality of present."

The dialectical tension described as "success/determination - wanting to give up" involves survivors' recovery process and willingness to keep attempting tasks, even when once-simple tasks become complicated and strenuous. "Isolated/loneliness - support" is a dialectical tension associated with interpersonal relationships. The feeling of isolation/loneliness involves the seclusion stroke survivors experience when they are not physically able to visit friends, are not visited by friends or family because the friends or family feel uncomfortable, and/or stroke survivors themselves do not want to see others due to pride. These feelings contrast with support, which is when family and friends are supportive and involved, and the stroke survivor is appreciative of the assistance offered by others. A third dialectical tension is "fear - content," which involves uncertainty 
regarding the future (e.g., the possibility of experiencing another stroke) versus the feelings of contentment with just being alive. A fourth dialectical tension is "independent - dependent;" this dialectical tension focuses on survivors' pre-stroke self-reliance versus the post-stroke reliance on others and coping with this transition. "Openness closedness" addresses stroke survivors' disclosure of information, including both quality and quantity, and amount of involvement with others. The dialectical tension of “thankfulness - frustration/anger” addresses stroke survivors' cognitive wrestling with negative feelings toward their current condition versus feelings of thankfulness when compared with others who are in worse health/medical situations. The seventh dialectical tension addresses stroke survivors" "reflections of past/reality of present." This dialectical tension involves feelings of frustration and sorrow regarding inability resulting from the stroke (e.g., ability to sew pre-stroke versus cannot sew because of paralysis post-stroke) and the realization that these abilities/skills will not return.

Survivors reported numerous examples of constant changes of feelings and emotions within these seven dialectical tensions. Consequently, Pawlowski’s (2006) research suggests stroke survivors are more reflective and, despite disability, view their overall quality of life in a positive manner. For example, many stroke survivors who once took life for granted now view their life as precious and attempt to make the most of it, despite any disability, and subsequent negative feelings, which may have resulted from the stroke. In addition, stroke survivors also reported more open communication with family members, a greater appreciation of family relationships, and an interest in selfpresentation, which includes the willingness to seek interpersonal support as well as more formal social support networks in order to perform daily functions. More specifically, 
from the dialectical perspective, "dialectical tensions felt by survivors within relationships were created out of necessity rather than by choice" (Pawlowski, 2006, p. 485). For example, in the "independent - dependent" dialectical tension, stroke survivors desire independence, but they must rely on others (e.g., caregivers) to function throughout daily life. Pawlowski (2006) also discusses the idea that, despite disability caused by a stroke, stroke survivors still desire and are able to contribute to society and interpersonal relationships, and quality relationships contribute to the recovery process and overall health of the stroke survivor. Finally, Pawlowski (2006) concludes her research with a call for further research which examines effects on the spouses/spousal caregivers of stroke survivors. Consequently, the focus of this research is to answer that call and identify the dialectical tensions prominent in the relationships between a stroke survivor and her/his spouse from the spouses' perspective.

\section{Dialectical Tensions Experienced by Spouses of Stroke Survivors}

As a result of the various and situation specific dialectical tensions which emerged in previous research, it can be assumed that the new and unfamiliar situation faced by a stroke survivor and her/his spouse would produce a unique set of dialectical tensions.

This study, being the first to focus on the dialectical tensions experienced by the spouses of stroke survivors, in addition to being related to the previously discussed article by Pawlowski (2006) regarding stroke survivors, is also related to Pawlowski’s (1998) study which focused on dialectical tensions in marital couples. Her findings suggest that in most healthy marital relationships, "autonomy-connection" is the most experienced contradiction, but "openness-closedness" is perceived by partners to be the most 
important. Moreover, Pawlowski (1998) found sex differences resulting in wives finding "inclusion-seclusion" and "revealment-concealment" more important than husbands. All of the research suggests that different relational situations can change the importance of different dialectical tensions or even produce unique dialectical tensions. In addition, Pawlowski (1998) shows perceptions of the individuals within the relationship can also result in different levels of importance for the dialectical tensions. Consequently, it may be assumed that stroke survivors' relationships will have unique dialectical tensions and the perceptions of their spouses' could differ from their own.

Despite the wealth of information on dialectical tensions in a variety of relationships, as previously discussed, sparse research has addressed dialectical tensions in health- and caregiver-related relationships, despite the benefits positive relational interactions are suggested to have on recovery and continued health (e.g., reduced stress, Palmer et al., 2004; improved quality of life, Bluvol \& Ford-Gilboe, 2004; Santos et al., 1999). In particular, research needs to be conducted in this area as the number of individuals affected by strokes, both as a survivor or the spouse of a survivor, will likely increase as a large portion of the population continues to age ("Healthcare braces for boomers," 2007), although age is not always a factor in susceptibility to stroke. Consequently, the following research question was posed:

RQ1: What dialectical tensions are experienced by the spouse of a stroke survivor?

In addition, as previously mentioned, Pawlowski's (1998) findings suggest that in most healthy marital relationships, the most common tension experienced is not consistent with the perception as to what is most important, which both spouses agreed 
upon. Thus, shared perceptions could be an important part of the stroke survivor/spouse relationship. Consequently, in an effort to determine if the perceptions held by stroke survivors (i.e., the seven discovered by Pawlowski, 2006) coincide with perceptions held by their spouse, the following research question was posed:

RQ2: How do the dialectical tensions experienced by spouses of stroke survivors compare to the dialectical tensions reported by stroke survivors in previous research?

Finally, as dialectical tensions have been different with various types of relationships, and relationships are characterized as constantly changing, it is also important to assess if these dialectical tensions change over time. Stroke is a situation which is unanticipated and often involves a great deal of change, not only physically but also relationally, for both the stroke survivor and her/his spouse/family (Palmer et al., 2004). Because RDT suggests that dialectical tensions within the relationship are constantly changing and cyclical (Harvey \& Wenzel, 2001), time since stroke may be a factor in the types and intensity of dialectical tensions experienced. As a result, the following research question was posed:

RQ3: How do spouses' dialectical tensions differ based on the length of time since the stroke? 


\section{CHAPTER 2}

Methodology

This study was conducted in a qualitative manner; consequently, information was gathered through interviews with stroke survivors' spouses. Information gathered through the interview process was coded, analyzed, and results are reported.

\section{Research Design}

A field study involving interviews with stroke survivors' spouses was employed to gather their thoughts and feelings regarding their current marital relationships. This method was employed due to a number of factors. Since this is the first study focusing on spouses of stroke survivors, a qualitative research method which gathers the experiences of the participants provides more information and insight than the constrained answers of a survey. In addition, this method follows previous research looking at stroke survivors and relational dialectic theory that have commonly employed open-ended questions (e.g., Pawlowski, 2006; Proot, ter Meulen, Abu-Saad, \& Crebolder, 2007). Moreover, by establishing a rapport with the participants through discussion and self-disclosure (e.g., personal reasons for conducting the research), there is an increased likelihood of collecting more in-depth information, such as personal experiences, emotions, and feelings, which provide the greatest insight into their lives and relational contexts (Lindlof, \& Taylor, 2002).

\section{Data-Gathering Methods}

Individual interviews were conducted with those individuals who desired to participate and met the qualifications (i.e., she/he is the spouse ${ }^{1}$ of a stroke survivor who was involved in a romantic relationship with the stroke survivor both prior to the stroke 
and currently). The participants were recruited through the distribution of fliers (see Appendix A) at stroke support group meetings and at an extended care facility in three mid-Atlantic states, which provided qualified participants with information about study participation. Participants were recruited until saturation occurred; however, based on previous research (Pawlowski, 2006), the target number of participants was at least 15. Ultimately, 16 individuals ( 10 women, 6 men) participated and ranged between 21 and 93 years of age ( $M=61.4$ years; $S D=18.86$ years $)$. The amount of time since the incident of stroke varied between 1 month and 12 years ( $\mathrm{M}=33.81$ months; $S D=41.13$ months), and the participants ranged from 7 months to 67 years of marriage $(M=29.73$ years; $S D$ $=21.78$ years $)$.

\section{Interviewing Procedures}

Participants received a cover letter describing the purpose and procedures of the study prior to their participation (see Appendix B). Interviews were audio recorded, with the informed consent of the participants, and later transcribed. Scratch notes were taken during the interview in case of technological malfunctions and in order to record aspects of participants' responses not attainable with audio alone (e.g., nonverbal expressions). Interviews were conducted at the convenience of the interviewee in a private area designated by the interviewee $(N=9)$ or via telephone $(N=7)$. In five instances, the stroke survivor was present during the interview due to extenuating circumstances; however, this did not appear to affect the level of disclosure when the length of interviews with spouses present ( $M=30$ minutes) was compared to the length of interviews without spouses present $(M=32$ minutes). Interviews were conducted using a semi-structured, open-ended interview guide (see Appendix C) which focused on 
rewards, difficulties, and relationship differences associated with being the spouse of a stroke survivor. Each participant was interviewed once and the length ranged between 13 minutes and one hour ( $M=32$ minutes). All information gathered during research, including but not limited to transcripts and audio files, was securely stored when not in use in an effort to maintain confidentiality. In addition, participants were assigned an identification number and pseudonym in an effort to maintain participants' privacy.

\section{Data Analysis Procedures}

As each interview was completed, the audio-recorded interaction was transcribed, and before analysis, the transcripts were checked for accuracy via reading while listening to the audio files. This resulted in 114 typed, single-spaced pages of transcripts. The transcripts were analyzed following standard qualitative research methods (Strauss \& Corbin, 1998). A constant comparative method was employed to detect recurrent dialectical tensions. Specifically, a detailed analysis was employed to develop categories. Data were inductively sorted into coding units, assigned a category, and compared within and across categories. Coding units were defined as each complete idea expressed by the interviewee. Thus, coding units consisted of a words, phrases, sentences, paragraphs, or multiple paragraphs. Similar coding units were grouped together to form categories. Each coding unit, which may not have been mutually exclusive, was placed in the appropriate category, and then transcripts were reread numerous times, using a comparative analysis, in an effort to identify common dialectical tensions. Topics that ceased to emerge were omitted, and recurring, relevant dialectical tensions were then classified into common dialectical tensions.

A portion of the transcripts were coded independently by me and my thesis 
advisor individually and then discussed and this process continued until all transcripts were coded. Intercoder reliability of all data was assessed using Scott's pi, which reached an excellent .94 (Scott, 1955). The relational tensions then were used to create a codebook and an independent coder (i.e., a trained research assistant) coded a portion of the data (i.e., 50\%) to further assess intercoder reliability. Scott's pi was calculated with the third coder's analyses and reached an acceptable .83 (Scott, 1955). 


\section{CHAPTER 3}

Results

Interviews with spouses of stroke survivors yielded insight into both the positive and negative aspects of being the spouse, and often the primary caregiver, of a stroke survivor. Surprisingly, regardless of length of time since stroke or number of years married, all participants held extremely positive views of their situation as the spouse of a stroke survivor. Overall, participants discussed rewards, difficulties, and relationship changes associated with being the spouse of a stroke survivor, and upon analysis the information yielded the following results.

\section{Research Question One}

The first research question was concerned with the dialectical tensions experienced by the spouses of stroke survivors. Coding and analysis of the interview transcripts revealed that spouses of stroke survivors deal with five common dialectical tensions: self-orientation - partner-orientation, realism-idealism, freedom-constraint, fear - content, and emotional release-emotional reservation.

Self-orientation - partner-orientation. The most common dialectical tension discussed by the participants was that of self-orientation-partner-orientation. All individuals discussed both their and their partner's needs/necessities and preferences/desires. Spouses did not hesitate to meet the physical and emotional needs, those components of life which must be met in order to avoid negative/undesired outcomes, of their partner. For example, spouses would physically drive their partners to appointments in addition to offering emotional support and encouragement regarding recovery and life in general. One individual (female, 40, 1.5 years since partner's stroke) 
stated:

I mean it's definitely a strain for us; it is. I think it's a strain for communication, you know, it's a strain on support for one another. I probably feel it's all kind of over to his side and not as much onto my side. Um you know, when he gets frustrated that I have to go into work, and it would be better for me to be at home. And, it's frustrating to be wanting to do your own job, and do something else, and deal with everything for day to day at home, and it's probably, I think, our communication is our hardest challenge because there's just so much we're dealing with ... just how emotionally how you support each other. It's hard when another person isn't, um I don't know, it's hard walking in without someone saying how was your day, what can I do for you, and how's it going? Instead it's pretty much coming home and dealing with parent stuff, and then saying so how was your day and what went well and what did not go well ... there's definitely been distance between us, you know, you're just so busy doing the day to day. So I think the communication goes down and the support, the emotional support, is one of it.

In the previous quote, the participant discussed her need for emotional support from the stroke survivor (self-orientation), and her willingness to overlook his inability to provide the support like he did prior to the stroke (partner-orientation). She also discussed having to take on more household responsibilities in addition to providing the stroke survivor with the increased emotional support he required (partner-orientation).

Surprisingly, spouses of stroke survivors also willingly forgo their own preferences (i.e., desire to have or arrange things a specific way) to meet the preferences 
their spouse's situation dictates. For example, one spouse (male, 42, 1 month since stroke) planned on building a deck on the back of their home; now post-stroke, his plan is to build a patio because it will be easier for his partner to get around with less worry of tripping. Another individual (female, 72, 12 years since spouse's stroke) stated:

I had to get rid of some furniture and change things around, do things in the bathroom so that he could ah operate, so that he could be helped to do the things that he needed to do ... well yeah, I regretted that. I mean, I had a piano and I had to get rid of the piano because it just took up too much room, and I was sorry about that, but it seemed at the time that, I mean, I didn't have much of a choice and I didn't, I mean, there was just nothing else to do. The decision had to go that way and it went that way.

This participant clearly had her own preference for what furniture she wanted in the house and how she wanted it arranged (self-orientation); however, she willingly rearranged and sold furniture for the stroke survivor's benefit (partner-orientation). Thus, we can see that the stroke survivor's preference (i.e., being able to navigate the living area easily) was met rather than the spouses preference (i.e., to have the piano in her home).

Again, self-orientation - partner-orientation was the most common dialectical tension and involved the spouse and her/his interpersonal orientation and the way the spouse involved herself/himself in the stroke survivor's situation. As one individual (female, 59, 3.5 years since spouse's stroke) discussed:

I continued to try and to work. I directed the nursery school, and I continued to try to work through that first year ... then, like by July, I just said I can't go through 
another school year like this because we were doing therapy ... that person's recovery and that person's survival just becomes your whole emphasis in life ... when I knew, you know, I wasn't going to go back to work that was a huge adjustment for me because, you know, I went from having a staff of 12 and 135 children in the program. You know, I had my whole purpose to be the caregiver, which I wouldn't have any other way, but it is different ... you begin five days of therapy, you know, we were driving 45 minutes to therapy and then back home. Um so it's a lot of hard work.

This participant expressed the desire to continue to work (self-orientation), but the strain on her physically and emotionally, resulting from the needs of the stroke survivor, required her to make a decision which ultimately provided for the stroke survivor's needs rather than her own (partner-orientation). Consequently, there is a clear dialectical tension that spouses of stroke survivors experience involving making decisions based on their preferences and/or needs and the stroke survivor's preferences and/or needs.

Realism-idealism. The second most common dialectical tension discussed was realism-idealism. The tension of realism-idealism is focused on three aspects: the past - present, present - future, and past - future. In regard to past - present, the spouse has to deal with her/his idealistic expectations of recovery and the conflicting realistic outcomes that are evident. Again, because of the unexpected and unpredictable nature of stroke, spouses of stroke survivors often look at the past and compare that to the current situation. For example, one spouse (female, 40, 1.5 years since stroke) stated: Yeah, I remember the first time I had him [help run an errand]. It was sometime I had to be to work and he was driving and he needed just like simple routes here. 
And he knew how to get to his job and how to get, maybe, to where I worked and how to get home and we had agreed we would try to have him meet me half way at a dance lesson and he would pick her [daughter] up and take her home. And, I'm thinking it's pretty straight forward from here to our house, it's not that far away; and, um he got lost and didn't know how to get home and my 8 year old was able to tell him because he didn't remember do we go here, do we go there. And, you know, people who know my husband knew actually one of his biggest strengths was his sense of direction. I mean he could get around in a city he had never been in amazingly well. He just had a fabulous sense of direction, and, um, to see him that just kind of hit me. I just thought how can you not, how do you not know how to get home ... it was hard, it was sad, you know, that was sad.

In this example, ideally the past abilities are desired, but realistically the present situation suggests they are not, and may never be, back. Consequently, the spouse of the stroke survivor experiences feelings of hope that the stroke survivor will regain all abilities she/he possessed prior to the stroke (idealism) but is often faced with signs which suggest a full recovery is not/may not be possible (realism).

The comparisons of present - future is where the spouse has a realistic and logical view of the stroke survivor's present status regarding the situation and/or recovery (realism) but has expectations of an ideal outcome which is very optimistic (idealism). For example, when discussing his wife's current status and her recent admittance to an extended care facility, one spouse (male, 65, 5 years since stroke) stated:

There is this continuous one thing I can say about emotions, there is one nagging emotion that always hangs in the back of your head and that is the possibility that 
she will get well enough to come home, which your intelligence tells you will never happen, but it hangs there. It's always there; I think it's just kind of a thing of not giving up hope; your psyche just doesn't want to give up hope.

In this example, the individual struggles with understanding that the stroke survivor's situation is one which has deteriorated over time and resulted in the need for constant, professional care (realism) and the desired/preferred outcome that the stroke survivor will one day recover to a level which will allow her to come home (idealism). Consequently, this exemplifies how present situations can be approached with realism, but despite these rational feelings, the spouse may focus on a future containing ideas/goals that are more representative of idealism.

The third component of this dialectical tension is the aspect of past - future. This component examines the past actions and abilities of the stroke survivor and/or couple (realism) and the level of recovery desired (idealism). For example, one spouse (male, 58, 2 years since spouse's stroke), when discussing a time when he realized life was going to be different, stated:

Probably when I realized that her recovery was going to be slower ... you have to start anew or try to bring back what there was, ya know, and uh that's what we're trying to do. We're still going to do the things we used to do ... We're going to do that, start doing that. So uh yeah, we're going to get back ... there's a goal up there one hundred percent. I mean, I don't care if ... way out of reach but that one hundred percent was up there um, ya know, whatever it took to get there that's what we're going to do.

In this example, the spouse expresses both an ideal future (i.e., "one hundred percent 
recovery," "going to do the things we used to do," "that's what we're going to do") and a realistic future (i.e., "I realized that wasn't going to happen," "start anew or try to bring back," "start doing that"). Overall, this aspect of past - future, within the realism idealism dialectical tension, is captured in the statement, "We're going to do that, start doing that." The ideal future is a return to a level of ability that was present prior to the stroke - a total recovery. The realistic future entails accepting the idea of starting over and developing a new set of expectations for the stroke survivor and her/his abilities.

Overall, the realism - idealism dialectical tension experienced by spouses of stroke survivors is one which permeates all levels of predicting/expecting and reflecting regarding the abilities of the stroke survivor and her/his recovery. In addition, the level of spouse involvement regarding the realism-idealism dialectical tension appears to negatively correlate with the length of time since the stroke, which is discussed later.

Freedom - constraint. The third most common dialectical tension was freedomconstraint. Again, due to the unexpected nature of stroke, the spouse, who prior to the stroke was able to be independent, must now consider the dependence of the stroke survivor and forego their once available independence. For example, when discussing the biggest difference in his life since his spouse's stroke, one individual (male, 58, 2 years since spouse's stroke) said:

The latitude I used to have, I don't have anymore. Ya know, it's because all our time is actually consumed with her recovery ... the freedom, the latitude to do the things that I used to do that now, I don't have the time to ... I have to pick special times or ya know pinpoint a time where I can do these.

In this example, the spouse expressed feelings of constraint (i.e., "The latitude I used to 
have, I don't have anymore," "time is actually consumed with her recovery ... the freedom, the latitude to do the things that I used to do that now, I don't have the time to"), which he expressed very clearly through his choice of words.

Another individual, when discussing loss of freedom stated, "It was just like a knife came down and cut off the life I had before and the life I had afterwards. I had to become an advocate for him" (female, 72, 12 years since spouse's stroke). Thus, in this example, another expression of feelings of constraint resulting from comparing past opportunities to participate in desired activities at will compared to now having to focus what used to be personal time on the spouse.

The main reason for this loss of independence, and resulting feeling of constraint, is the need to be available to care for the stroke survivor. Spouses sometimes referred to themselves as 24-hour therapists and because of the intensity of the situation felt as though taking care of their partner is another job. One individual (female, 72, 12 years since spouse's stroke) echoed this saying:

What I lost most of all was my freedom; I lost my own life. I lost my ability to control my time, and there are things that I wanted to do when I wanted to do them and I had to always I had a job that was 24 hours 7 days a week 365 days a year that I never got anytime off from and I still have that.

In this example, the spouse expresses feelings of constraint (i.e., "I lost my own life") and identifies the reason she feels constrained (i.e., "I had a job that was 24 hours 7 days a week 365 days a year that I never got anytime off from").

Nearly all participants expressed some type of loss of freedom. Depictions included: "if you become the caregiver of that spouse she or he even controls even more 
of your life so that your only life is that person and that person's needs" (male, 65, 5 years since spouse's stroke), “that person's recovery and that person's survival just becomes your whole emphasis in life" (female, 59, 3.5 years since spouse's stroke), "my life changed completely. I had to take total care of him physically ... He had to go with me everyplace" (female, 74, 7 years since spouse's stroke), "I am going to have to change my life ... put self on hold ... a life style of no freedom" (female, 61, 2 months since spouse's stroke), "not having much time for yourself" (female, 40, 1.5 years since spouse's stroke), “you can't do you can't leave you can't go to the other room ah unless you know for sure that that everything's okay that everything looks okay" (female, 76, 1 year since spouse's stroke), and:

I stay home all the time. I stay with him all the time ... it's just changed our lives completely. I stay at home all the time. I never leave maybe just to go to the grocery store; we have somebody who comes in and stays with him otherwise I take care of him. (female, 93, 5 years since spouse's stroke) In addition to individual freedom, participants also expressed a loss of freedom as a couple. An example of this is travel, such as winters in Florida (female, 93, 5 years since spouse's stroke). Some individuals not only expressed the loss of the freedom to travel, but also the loss of participating comfortably in some social environments and/or situations. While discussing how her life had been most affected since her spouse's stroke, one individual (female, 61, 1 year since spouse's stroke) said, “Traveling ... and namely going to a restaurant. He feels that's frustrating for both of us." Another individual (female, 59, 3.5 years since stroke) stated:

And we have since moved to a 55 and older community, and there's a lot of social 
activities here and they're just, they're not comfortable because, you know, I know that if I go to something like that the newness of the situation, the people that he really doesn't know, I have a hard time enjoying myself because I know he's not comfortable, and, you know, the frustration I guess that comes, comes along with that.

In this example, the couple experiences constraint through the lack of social involvement resulting from feelings of discomfort from both the spouse and the stroke survivor (i.e., "I have a hard time enjoying myself because I know he's not comfortable").

Furthermore, some individuals also expressed a loss of freedom regarding future plans/options regarding both self and couple. When discussing how she envisioned her future, one individual (female, 59, 3.5 years since spouse's stroke) stated:

I probably, if I didn't do that [nursery school director] I would've done something else, you know. I had been a nursery school director for 30 years and um I had thought about maybe doing something different but [he] would have kept working so, so even if I had cut back, or you know done something a little bit different, he would have worked. So we both retired.

In this example, if the husband had not experienced a stroke, the spouse would have had the freedom to choose another profession after retiring from teaching; however, because of the husband's stroke and his inability to work, the spouse now feels she cannot take on another job (constraint). Another individual (female, 72, 12 years since spouse's stroke) expressed similar feelings by saying:

I kind of had envisioned a different sort of life for myself, and I have had to give up a lot of things that I wanted to do. I am retired now. When he had the stroke, I 
was working. I worked about seven years after that time, but I'm retired now and I had a lot of plans for what I was going to do when I retired. I was going to learn to play the cello and you know there's a bunch of silly stuff like that, and I just had to give up all those things.

Thus, the individual struggles with how she desired to spend her retirement (freedom) and how she is actually spending it (constraint). Consequently, the effect of stroke on the spouse and the couple as a whole, in regards to freedom and the resulting constraint, is evident.

Fear-content. All of the spouses discussed some degree of fear. This fear often resulted from uncertainty regarding a given situation (e.g., is my wife/husband going to live, how much will she/he recover, what am I going to do when she/he comes home). Fear was most often related to the initial episode when the stroke took place and awaiting diagnosis, and later fear of another stroke occurring surfaced. In regard to the initial episode, individuals employed terms such as, "absolute terror" (male, 58, 2 years since spouse's stroke), “scared to death" (female, no age given, 3 months since spouse's stroke), “overwhelmed” (female, 61, 1 year since spouse's stroke), "freaking out" (female, 42, 1 month since partner's stroke), "helpless" (male, 21, 2 months since spouse's stroke), “traumatic" (female, 76, 1 year since spouse's stroke), "staggering” (male, 42, 1 month since spouse's stroke), and "state of shock" (female, 59, 3.5 years since spouse's stroke). As for fear/uncertainty regarding another stroke, most merely made a statement like, "What am I going to do if this happens again?"

In regard to feelings of contentment/relief, most expressed this in relation to the fact that their partner was still alive post-stroke. One individual (male, 21, 2 months since 
spouse's stroke) stated:

You realize how blessed you are to have them ... she was at a place where the doctors basically wanted us to give up ... had we given up at the time that they wanted us to we would be going to a local cemetery somewhere to visit her instead of here [extended care facility] and things are a lot better than they could have been.

In this example, the spouse experiences feeling of relief and gratitude at the stroke survivor merely being alive and having the opportunity to see her (content). In addition to contentment because the stroke survivor is still alive, others discuss the contentment/relief regarding the stroke survivor's recovery: "you're kind of in the stage of emotion that says well we're glad that she's coming along as good as she is" (male, 65, 5 years since spouse's stroke). Overall, this dialectical tension deals with the individual fluctuating between the situational unknowns and the situational outcomes. One individual (male, 58, 2 years since spouse's stroke) exemplifies this dialectical tension by saying:

Fear, absolute fear, unknown ... I really thought she was gone, I really did and uh things work out ... But uh yeah it was absolute terror in the beginning ... There was there was a relief but also the fear was still there. Uh the unknown, ya know? What am I going to do if this happens again, ya know?

This quote exemplifies not only the dialectical tension of fear-content but also the nature of dialectical tensions (i.e., their fluctuating and fluid nature). The spouse initially expresses an experience of "absolute fear" (fear), followed by feelings of relief (content), followed again by feelings of fear (i.e., "What am I going to do if this happens again?"). 
Consequently, it is evident that spouses of stroke survivors not only experience fear but also experience content and fluctuate between such feelings.

Emotional release - emotional reservation. The fifth and final dialectical tension to emerge was emotional release-emotional reservation. Many of the individuals discussed instances where they either released and experienced their emotions or reserved and contained their emotions. For example, regarding expressing emotions, individuals made statements such as, "I would cry and then I would think and then I would cry and then I would think" (female, 42, 1 month since partner's stroke) or "I prided myself on being able to maintain my composure and not lose control of my emotions and I completely, I made it to the hospital and when I saw her, I mean I lost control of my emotions" (male, 74, 7 years since spouse's stroke). In fact, when discussing what advice she would give someone else whose spouse just had a stroke, one individual (female, 61, 2 months since spouse's stroke) suggested, "cry," and other individuals actually cried or nearly cried during the interview (e.g., male, 58, 2 years since spouse's stroke; female, 59, 3.5 years since spouse's stroke; female, age not given, 3 months since spouse's stroke). However, crying is not the only emotional expression/emotion spouses struggle with in regard to reserving versus releasing. One individual (female, no age given, 3 months since spouse's stroke) stated, "He was so mean. He yelled all the time ... I finally threw a fit and yelled at [him]." In this example, the spouse attempted to conceal her anger/frustration regarding the stroke survivor's attitude and behavior (i.e., "He was so mean" and she typically did not respond) (emotional reservation), but finally could not contain the feelings any longer and expressed how she felt (i.e., "I finally threw a fit and yelled") (emotional release). 
In relation to the previous situation, but dealing more with emotional reservation in the presence of the stroke survivor, another individual (female, 61, 1 year since spouse's stroke) stated, "he would get mad at me and I had to walk away because I'd get upset." Thus, this individual would get upset (i.e., experience some type of negative emotion regarding the situation) and she would have to walk away so as to not express her feelings to the stroke survivor (emotional reservation), but by being upset, even though she is not in the presence of the stroke survivor, she actually expressed the emotions (emotional release), however, not in an emotionally supportive environment.

As opposed to emotional release, other individuals also discussed the idea of emotional reservation, or not reacting to a situation and letting your emotions show. One individual (male, 42, 1 month since spouse's stroke) stated, "Never let the stroke victim see your weakness," while another (female, 93, 5 years since spouse's stroke) stated, "You just have to grin and bear it and try not to think about it." Overall, this reservation aspect of the dialectical tension is exemplified by an individual (male, 21, 2 months since spouse's stroke) who said:

The most difficult is not really having an outlet for my own emotions, and for I basically since all this started 10 weeks ago, I've kind of just had to bottle things up sometimes because I have to stay strong around her. I've always taken it upon myself to be the strongest person in a situation and though that may not be the healthiest thing to do that's who I am. You know I just kind of swallow my pride so to speak or swallow my emotions and just go on.

In this example, the spouse discussed an inability to experience emotional release (i.e., "not really having an outlet for my own emotions") because of a need to appear 
emotionally stable around the stroke survivor despite the negative health implications of doing so (i.e., "though that may not be the healthiest thing to do").

Furthermore, another individual (female, 40, 1.5 years since spouse's stroke) exemplified this dialectical tension by stating:

It's kind of hard not to get frustrated; and, I still catch myself. Something happened just the other day when he asked me and I thought, know you, he asked me that twice, so I'm not going to snap at [him], and just have to swallow it, and just look at [him], and just tell [him], very calmly, what the answer is. Because, I think, in the beginning, I could just, it would just make me nuts. I couldn't believe how could [he] not remember? I just told [him]. And that wasn't fair to him, and because then he'd see I'd get frustrated and angry ... and I just thought I can't do this you know? So I think it's hard. You go through a lot of frustration and anger, and I realize he's going through the same thing and it's not his fault.

In this quote, the individual did express her frustration initially (emotional release) and would like to still express it, but now she recognizes that the stroke survivor is not doing things purposefully and that expressing her emotions was unfair to him. Consequently, she realizes that emotional reservation is the best option for the stroke survivor and disregards her own desire (emotional release) for his benefit.

Overall, this dialectical tension deals with the individual fluctuating between releasing and expressing their emotions and reserving and avoiding expressing their emotions. In addition, spouses often consider the impact of either releasing or reserving their emotions on the stroke survivor, rather than themselves.

Overall, the disclosures of spouses of stroke survivors suggested they commonly 
experience five dialectical tensions: self-orientation - partner-orientation, realism idealism, freedom - constraint, fear - content, and emotional release - emotional reservation. Self-orientation - partner-orientation appears to be the most common dialectical tension experienced by the spouses of stroke survivors followed by realism idealism and freedom - constraint. The dialectical tension of fear-content is not as common as the others but is generally expressed in regard to the initial experience of her/his spouse experiencing the stroke or fear of the stroke survivor having subsequent strokes. The least common dialectical tension experienced by spouses of stroke survivors was emotional release - emotional reservation; much like fear-content, this dialectical tension was commonly discussed regarding the initial experience of her/his spouse's stroke but also appeared during the recovery and adjustment to changes in lifestyle/homelife.

\section{Research Question Two}

The second research question posed for this study focused on similarities between the dialectical tensions found to exist in spouses of stroke survivors and those found, in a previous study (Pawlowski, 2006), to exist among stroke survivors. As previously discussed, previous research focusing on dialectical tensions in stroke survivors by Pawlowski (2006) discovered seven dialectical tensions commonly exhibited by stroke survivors: "success/determination - wanting to give up," "isolated/loneliness - support," "fear - content," "independent - dependent," "openness - closedness," "thankfulness frustration/anger," and "reflections of past/reality of present."

Throughout the process of examining the dialectical tensions discovered by Pawlowski (2006) and coding and analyzing the transcripts from this study, it became 
apparent that, although spouses of stroke survivors did not have to deal with the physical experiences (e.g., paralysis of a hand, memory problems) and the emotional issues (e.g. depression, low self-esteem) which come with such impairments personally, both spouses and stroke survivors do experience similar dialectical tensions. The tensions which are similar include: "fear - content" in stroke survivors (Pawlowski, 2006) and fear-content in spouses of stroke survivors, "success/determination - wanting to give up" and "reflections of past/reality of present" in stroke survivors (Pawlowski, 2006) and realism - idealism in spouses of stroke survivors, and "isolated/loneliness - support" and “independent - dependent" in stroke survivors (Pawlowski, 2006) and freedom constraint in spouses of stroke survivors. The dialectical tensions which exhibit the most commonality among both stroke survivors and their spouses are fear-content.

According to Pawlowski's (2006) research, the dialectical tensions of "fear content" exhibited by stroke survivors most commonly dealt with uncertainty regarding the future, including the fear of having another stroke to the ability/inability to provide for their family, and a feeling of joy and contentment because they are alive. Pawlowski (2006) exemplified this concept in a quote by one stroke survivor saying:

"I don't know if and when it will happen again - I should not have had the first one. No one knows why - I was healthy and didn't smoke or drink. It just hit me one day - so that's always on my mind. I was worried that we would not make it financially, but we have just had to live within our means since the stroke - I know I have to live life to its fullest because I don't know what tomorrow will bring and it scares me sometimes." (p. 481)

This stroke survivor exhibits the flow of emotions between fear and content by 
questioning why/worrying it will happen again and accepting the situation/being thankful for the opportunity to live.

In relation to this dialectical tension felt by the stroke survivors, the dialectical tension of fear-content in regard to spouses, which emerged in this study, is similar to Pawlowski's (2006). Fear-content on the part of the spouse most often resulted from uncertainty regarding a given situation (e.g., is my wife/husband going to live, how much will she/he recover, what am I going to do when she/he comes home). Moreover, fear was most often related to the initial episode when the stroke took place and when awaiting diagnosis and fear of another stroke occurring. One spouse (male, 74, 7 years since spouse's stroke) when discussing the most difficult aspect of being the spouse of a stroke survivor actually stated, "constant fear that she would have another stroke," acknowledging the fear and from where it stemmed. In relation to content, spouses, much like stroke survivors, often expressed this as thankfulness for the continued life. One individual (female, 74, 7 years since spouse's stroke) stated, "I was just glad to have him. I was glad he was alive," acknowledging a level of content at merely having them alive regardless of the fear and trials and tribulations which have to be faced regarding recovery.

In addition, two of the dialectical tensions of stroke survivors discovered by Pawlowski (2006), "success/determination - wanting to give up" and "reflections of past/reality of present," are most closely related to the realism-idealism dialectical tension expressed by spouses of stroke survivors. These dialectical tensions, which were expressed in both stroke survivors and their spouses, although not explicitly similar, dealt with recovery. Pawlowski (2006) noted the dialectical tension "success/determination- 
wanting to give up" which involves the survivors' recovery process and the willingness to keep attempting tasks, even when once-simple tasks become complicated and strenuous. Pawlowski (2006) quoted one individual as saying:

"Some days I get so damn mad - one day, I tried to get my shirt buttoned and she was gone for a while. I must have spent 15 minutes trying to get it buttoned. I finally had success and got the darn thing buttoned - I was exhausted and had to sit down for a while but at least I dressed myself." (p. 479)

Thus, there is a dialectical tension between giving-up, which would lessen the frustration and avoid feeling physically exhausted, and being determined to complete a task which was once commonplace and routine.

Moreover, a second similarity between dialectical tensions experienced by stroke survivors and those experienced by their spouses relates to Pawlowski's (2006) dialectical tension of "reflections of past/reality of present." This dialectical tension involves feelings of frustration and sorrow regarding inability resulting from the stroke (e.g., ability to button a shirt pre-stroke versus cannot dress self post-stroke because of paralysis) and the realization that these abilities/skills will not return. Pawlowski (2006) quoted one stroke survivor as saying:

"She [the occupational therapist] would come over every day and work my leg and arm - I was kinda still hoping I would be okay and I was going back to work next month - that's what I had on my mind. One day she says to me, 'What if it does not get better?' and geez I got mad at her and said never to talk negative like that again. Then for some reason that was the day that I finally accepted the fact that maybe I wasn't going to get good again. Once I accepted it, that was the 
biggest step. I didn't give up or quit therapy - I just had a reality check and had to move on.” (pp. 483-484)

Here is an example of the stroke survivor facing reality and moving from a past focused and idealistic view of his recovery (i.e., returning to "good again" and to work) to a view with more awareness of the situation and realistic expectations.

These dialectical tensions in stroke survivors are related to the dialectical tension of realism - idealism because spouses often encompassed both a recovery and a past present, present - future, past - future comparison. In regard to recovery and the ideal level of success versus the realistic level, one spouse (male, 74, 7 years since spouse's stroke) stated:

She worked real hard with the hopes that she would regain the use of her arm and leg, and you know, and everything would come back. We worked like the devil for the first couple of years trying to make things happen that weren't going to happen, but ah hopefully. Well, I always, I think we were on the same page whenever we began to face reality. We didn't, there wasn't a discussion with us back and forth, but we just kind of ah, I felt I kind of based myself on her and just started. She didn't verbalize this, but she started recognizing that it was fruitless. And, she tried her damnedest to try to continue to expect some miracle to get her arm back, and that poor thing. So we ah backed off on that. We still, we're following, what we do is the latest information that we get from the stroke association and, ah keep, that's just the new arm, but we're um, we're pursuing that, but we're not expecting an miracles anymore, but um I think we I guess I say we're being more realistic about her situation. 
This spouse had an ideal level of recovery success but a realistic view of when to backoff and give up some expectations. This relates to the dialectical tension the stroke survivors expressed regarding Pawlowski’s (2006) dialectical tension of "success/determination - wanting to give up" and "reflections of past/reality of present." Consequently, the relationship between these two dialectical tensions exhibited by stroke survivors, as identified by Pawlowski (2006), and the dialectical tension of realismidealism, as identified in this study, can be seen as similar.

The final dialectical tensions which are similar between both the stroke survivor and her/his spouse involve two other dialectical tensions found in Pawlowski's (2006) study. These dialectical tensions are "isolated/loneliness - support" and "independent dependent." These two stroke survivor dialectical tensions and the freedom - constraint dialectical tension among spouses, which is a complement to those found in the stroke survivor, are related but not exactly the same. In regard to the feelings of isolation, one stroke survivor in Pawlowski’s (2006) study stated:

“I miss not having company - and I love to visit. People just don't visit with us like they used to - or when we get together [with friends] and they go for a walk I am not able to do that. I used to play a lot of cribbage, but now I can't hold the cards so I don't play cribbage. Our daughter bought me a cardholder, but it's not the same as being able to hold the cards yourself. So many of our card players just don't come by much.” (Pawlowski, 2006, p. 480)

The stroke survivor experienced feelings of isolation and loneliness because not only do people no longer visit who used to, but also in situations where others are around, they participate in activities which the stroke survivor is unable to do (e.g., walk). In contrast, 
one stroke survivor expressed his appreciation of support by saying:

"My kids and neighbors are great - one day I was trying to mow the lawn and fell on the mower. My neighbors came to help me up - they are always looking out for me when I am in the backyard. There isn't anything I could not ask them to do, and the kids have been great. The boys came to fix up the house - putting in hand rails, making the bathroom bigger, fixing stuff around the house - that I used to be able to do. I don't know what we would do without them. It used to bother me to ask them for anything but everyone just pitches in now and knows that I can't do it on my own.” (Pawlowski, 2006, p. 480)

Thus, the stroke survivor exhibited the need and acceptance of support offered by a support network which includes both family and friends.

In regard to the stroke survivor dialectical tension of "independent - dependent," which focuses on the survivors' pre-stroke self-reliance versus the post-stroke reliance on others and coping with the transition from self-reliance to reliance on others, one stroke survivor stated:

"I guess I miss the competitive things I used to do like hunting and fishing and playing ball and stuff like that. Back before my stroke - I had everything - at the drop of a hat I could go. Now before I can do stuff like that I have to try to organize it and make sure I have the right equipment - and many times am now the spectator. I guess probably more than anything, I miss the spontaneity. Now I have to plan and schedule everything." (Pawlowski, 2006, pp. 481-482) This quote, where the stroke survivor expressed his previous independence and present dependence regarding participating in activities, not only exemplifies Pawlowski's (2006) 
"independence - dependence" dialectical tension but clearly relates to the dialectical tension of freedom - constraint discovered in this study.

The dialectical tension of freedom - constraint is due to the unexpected nature of stroke, and the fact that, prior to the stroke, the spouse was able to be independent, but now, post-stroke, must consider the dependence of the stroke survivor and forego her/his once available independence. One quote, which exemplifies this and relates well to the aforementioned stroke survivor's quote, resulted from the spouse discussing the biggest difference in his life since his spouse's stroke. The individual (male, 58, 2 years since spouse's stroke) stated:

Like fishing, for example, I got to plan ahead way ahead, ya know, just to go for one afternoon or something, ya know, because I got to make arrangements ... yeah, but freedom. Loss of freedom.

Thus, the spouse, much like the stroke survivor, has to plan and schedule, more so now than prior to the stroke, in order to participate in the same activities which results in feelings of constraint. In addition, because the spouses of stroke survivors forgo their independence in an effort to care for the stroke survivor, the spouses often discussed how the support of family and friends was helpful in achieving some semblance of freedom. One individual (female, 7 years since spouse's stroke) stated:

He had to go with me every place ... I took him every place ... I made him go play golf. I'd have men pick him up, his friends, old friends, and they'd pick him up, and they'd play golf with him. And then they'd bring him home and that would give me a day off to go to the mall.

So here it is apparent that the support of others allowed her to participate in the activities 
she once enjoyed while getting to experience some of the freedom she once had.

In relation to the constraint felt by spouses due to a lack of freedom, another component of the constraint is related to the isolation and unwillingness/inability to participate in social situations due to a feeling of concern for the feelings of the stroke survivor. As previously mentioned, some spouses of stroke survivors experience these feelings of isolation due to the self-selected decision to avoid some social situations because of concern for the comfort/discomfort of their spouse in such a situation; however, some spouses discussed feelings of isolation due to a lack of inquiry from friends and family regarding their feelings. One individual (female, 59, 39 years since stroke) stated:

When you are the caregiver, you are very isolated. It can feel very, very isolating and so I think, you know, people need to be aware of that, and I think um what I got upset about early on is that everybody's always concerned about, you know, the person who had the stroke (begins to cry) and they forget, they forget to ask about the caregiver.

The spouse experienced feelings of isolation because of a lack of concern for her feelings and physical condition from others who appear to care about the situation but not her individually like they do the stroke survivor. Consequently, the connection between Pawlowski's (2006) dialectical tensions for stroke survivors of "isolated/loneliness support" and "independent - dependent" and the dialectical tension for spouses of freedom - constraint is exemplified in the disclosure of the participants and supports the recognition of this tension.

Overall, the dialectical tensions experienced by spouses of stroke survivors appear 
to be related to those experienced by the stroke survivor; however, these dialectical tensions are not exactly the same. It appears that the dialectical tensions experienced by the spouse are a complement to those experienced by the stroke survivor. For example, the stroke survivor experiences a loss of freedom and increased dependence as a result of the effects of the stroke. The spouse generally experiences the impact of the stroke survivor's increased dependence and consequently experiences a loss of freedom as a result. Thus, although the dialectical tensions do not stem from the same catalyst, both the stroke survivor and the spouse experience some similar dialectical tensions as well as those that are role specific.

Research Question Three

Research question three involves determining whether time has an effect on the dialectical tensions experienced by the spouses of stroke survivors. Due to the unexpected nature of stroke, people are not prepared for the situation; however, the farther removed they are from the initial incident, the more they begin to understand how to deal with being the spouse of a stroke survivor. After coding and analyzing the interview transcripts, it is apparent that time does affect the attitudes of the spouses regarding the dialectical tensions of realism-idealism and fear-content.

The realism-idealism dialectical tension appears to be affected by time in a manner which suggests that as time increases, the degree of realism regarding level of recovery increases. For those individuals whose spouse experienced a stroke less than one year ago, the level of idealism is the highest. For example, one individual (male, 21, 2.5 months since spouse's stroke), when discussing how he thought life was going to be different, said, "We have faith that everything is going to be back to normal over time ... 
Everything's going to be okay, you'll be back to normal you know in a few months; you'll never even know it happened." In this example, the ideal level of recovery is a total recovery with no mention of a less than total recovery being a possibility.

The time between one year and four years appears to be a transition phase where some individuals progress towards a more realistic view faster than others. For example, one individual (male, 58, 2 years since spouse's stroke), while discussing the time he realized life was going to be different after his spouse's stroke, stated:

I was thinking on terms of maybe a year things would be back to one hundred percent normal and uh ... I realized that wasn't going to happen and uh, it's not that she's not recovering ya know, it's just not as fast as I thought it would be. Thus, the spouse is moving back and forth between an idealistic (i.e., "one hundred percent normal") and a realistic (i.e., "I realized that wasn't going to happen," "it's just not as fast as I thought it would be") view of the stroke survivor's recovery but with the idealism still being more pertinent. In relation to the progression toward realism experienced during this time period, another individual (female, 59, 3.5 years since spouse's stroke), while discussing when she realized life was going to be different and the intense push for the stroke survivor's continued therapy and recovery, stated, "maybe there's a little denial that goes along." At three and a half years since the spouse's stroke, she is beginning to recognize more fully that a complete recovery is not possible and the idealistic expectations may not be achievable; however, she has not completely accepted the idea as she mentions the use of denial.

The time period of greater than four years since the spouse's stroke is where the most realistic views of recovery are evident. For example, one individual (male, 74, 7 
years since spouse's stroke) stated, "We're not expecting any miracles anymore, but um I think we, I guess I say, we're being more realistic about her situation.” Thus, although there is still hope for recovery, the realistic view of what is possible is much more pertinent than a more idealistic view.

Similar to realism - idealism, the fear-content dialectical tension appears to be affected by time in that the fear appears to be most intense initially and becomes less intense over time but continues to persist. Again, like with the realism-idealism dialectical tension, spouses can be broken down into three groups: less than one year, one to four years, and greater than four years. Those individuals whose spouse had a stroke within the past year often expressed experiencing high levels of fear. When discussing how she felt when she found out her husband had a stroke, one individual (female, age unknown, 3 months since spouse's stroke) said, "I cried all the time, um scared to death because you don't know what's going to happen next, and his mom has had five so there's a good chance this is not the last one." Consequently, this individual experienced the largest amount of fear over concern of losing the stroke survivor and the fear of another stroke. These were the most common reasons for fear expressed by individuals with spouses who had a stroke less than one year ago.

Most of the individuals in the one to four year range, much like with the realismidealism dialectical tension, still expressed experiencing fear but not as intensely as those who fell into the less than one year category. For example, one individual (female, 59, 3.5 years since spouse's stroke), when discussing what it was like when the stroke survivor came home, stated:

It was scary because you don't know what he can do, you know, they teach you 
before you leave rehab how to get him up after a fall. Um, I can remember um, you know, at night hoping he could get up and get to the bathroom and back if the lights weren't on. You know, you're not sure you can leave him, but you think you can and you know he was fairly mobile by the time he got home.

Rather than a fear of death or reoccurrence, this individual has a fear regarding the stroke survivor's ability to be independent. Overall, this category of one to four years is a time of transition as those who are closer to one year still have the fear that another stroke will occur, but as time since the initial stroke increases, the fear of reoccurrence appears to decrease.

Those individuals included in the category of greater than four years since the spouse's stroke generally expressed more content than fear. In fact, fear, if mentioned, was discussed in more of a reminiscent tone. One individual (male, 74, 7 years since spouse's stroke), while discussing the most difficult part of being the spouse of a stroke survivor, stated, "Ah, for me it is not so much now, but early months, years and all that constant fear that she would have another or she would - she had, Minnie ${ }^{2}$ had a series of falls too." Thus, although he once experienced fear regarding reoccurrence and recovery, much like those in the four years and less categories, he now expressed a move beyond that fear. In addition, regarding contentment, one individual (female, 74, 7 years since spouse stroke) stated, "I was just glad to have him. I was glad he was alive, and I did everything I could to keep him that way." Thus, she had moved to contentment at his presence rather than fear that something will happen. Consequently, the greater the amount of time since the spouse's stroke, the greater the feelings of content and fewer fearful feelings. 
One additional area where a slight affect on time is evident is in regard to the dialectical tension of freedom - constraint. This area does not have the same division of time as the other tensions affected by time but rather is more dependent on the stroke survivor's level of recovery and needs. Consequently, some spouses regain freedom more quickly than others. Generally, spouses of stroke survivors appear to lose most of their freedom initially. For example, one individual (female, 42, 1 month since spouse's stroke), when discussing her daily routine, stated:

I come, like I said, I get up at 3:00 in the morning and I leave the house at 5:00 and I'm here at 6:00 or 6:30 and I don't leave until 7:30 or 8:00 in the evening. I'm with him all day long ... whatever he needs I will fight for him here. Thus, at the present time, because of her commitment to providing support and being an advocate for the stroke survivor, she has very little freedom. However, it appears that the amount of time since the stroke positively correlates with amount of freedom for the spouse of the stroke survivor. Another individual (male, 83, 4 years since spouse's stroke), in regard to regaining freedom, stated:

She's a great cook and ah she goes and does the shopping. Originally, I did all the shopping there for a while, but as soon as she could, she took over and um she goes shopping and comes back with pretty things and so on and she's my social secretary.

This quote illustrates that while at one point the spouse's freedom to do what he desired with his time was consumed completing the tasks that were once the stroke survivor's responsibility, as time has progressed, the stroke survivor has recovered to a level where she can resume those responsibilities and the spouse has an increased level of freedom. 
Other than an increased degree of recovery, the other factor which can immediately and intensely affect the spouse's level of freedom is the need to place the stroke survivor in a long-term care home. One individual (male, 65, 5 years since spouse's stroke) discussed having to place his wife in a long-term care home after four and a half years of caring for her because her condition worsened to the point that he could no longer care for her by himself. By placing her in the long-term care home, he immediately increased his level of freedom and began to do more for himself and his own health, despite not necessarily wanting to place her in the long-term care home.

Overall, level of freedom and time since stroke appear to positively correlate; however, there are exceptions such as a slow recovery rate and limited overall level of recovery. Also, in some situations spouses need to place the stroke survivor into a longterm care home, which causes an immediate, although often less than pleasing, increase in freedom for the spouse. Ultimately, it is the severity of the stroke and the area of the brain which was affected that influences the level and the speed of the stroke survivor's recovery, which appears to be the key factor in the spouse regaining freedom.

The overall effect of time on spouses of stroke survivors suggests that the spouses transition from being overly optimistic regarding level of recovery to holding a more realistic view of the skills the stroke survivor can actually recover; however, it is important to note that none of the participants expressed a view which portrayed a total loss of hope for further recovery. In addition, the examination of time since the stroke survivor's initial diagnosis suggests that spouses transition from being more fearful to being more content regarding the stroke survivor's well-being. Finally, time also affects the level of freedom - constraint spouses experience. Although the amount of time varies 
greatly based on severity of stroke and speed of recovery, spouses of stroke survivors expressed an increase of freedom, which was related to the stroke survivor's recovery. Consequently, there is a clear connection between changes in the intensity of dialectical tensions experienced by spouses of stroke survivors and the amount of time since the spouse's stroke. 


\section{CHAPTER 4}

Discussion

The purpose of this study was to discover what dialectical tensions are experienced by spouses of stroke survivors. In addition, I examined how the dialectical tensions of stroke survivors, discovered in previous research (Pawlowski, 2006), compared with those experienced by spouses of stroke survivors and what affect time had on the dialectical tensions experience by the spouses of stroke survivors. Ultimately, five dialectical tensions emerged: self-orientation - partner-orientation, realism - idealism, freedom - constraint, fear-content, and emotional release-emotional reservation. Consequently, I present the following implications of the data, strengths and limitations of the study, and future research directions for this area of study. Implications of the Data

The primary benefit of this research is the positive health implications for spouses of stroke survivors resulting from providing them with this information. Most participants expressed the need to be provided with information regarding what is "normal" for them to experience in their situation. Many stated that the medical professionals needed to provide them with more information on how to manage the situation. Moreover, those who had recently become the spouse of a stroke survivor, often hedged responses by saying what they felt probably was not normal or they felt ashamed for feeling the way they felt, thus, creating stress and negative feelings. As previously mentioned, high levels of stress have negative health implications, such as increased arousal and increased blood pressure (Brereton, 1997). By knowing what type of feelings they may experience during such an uncertain and unexpected time, spouses of stroke survivors would feel less 
uncertainty, which would ultimately result in lower levels of stress.

In addition to health implications, this data also suggest that stroke survivors and their spouses experience some similar feelings. Thus, a situation that may seem like the spouse cannot relate to the stroke survivor could be one where both the spouse and the stroke survivor are experiencing similar feelings. Knowing that they are experiencing similar feelings could lead to the spouse and the stroke survivor increasing communication and self-disclosure and ultimately finding support in one another and increasing their relational closeness. As previously discussed, Pawlowski (1998) found that "autonomy - connection" was the most common contradiction experienced by marital partners in a healthy relationship, despite "openness - closedness" being reported as the most important dialectical tension in such relationships. Consequently, by realizing their partner is experiencing similar feelings, the stroke survivor/spouse can increase both connection and openness creating a more understanding, positive relational atmosphere and healthy marital relationship despite other difficulties (e.g., difficult therapy/recovery, changes in living arrangements).

Finally, the data suggest that stroke is not an event that causes the spouse to become confined for the remainder of her/his life. Findings suggest that although there is a loss of freedom initially, over time freedom for the spouse and/or the stroke survivor slowly increases as the spouse mentally releases from the situation (i.e., not wanting to leave their side for fear of recurrence to being able to spend time away from the spouse without overwhelming worry/fear). Consequently, the knowledge that both members of the relationship experience a dialectical tension which deals with these feelings, coupled with the knowledge that over time freedom appears to increase, could increase the hope 
and determination of both members of the couple.

\section{Strengths and Limitations}

One strength of this study was the sample size and diversity of the sample.

Previous research employed 15 participants (Pawlowski, 2006), while the current study employed 16 participants, which when considering the unpredictable nature of stroke causes difficulty in regard to finding qualified participants. Despite this difficulty, and although the sample was not ethically diverse, the participants in this study represented a diverse group. Participants were recruited through three mid-Atlantic states and the age ranged from 21 to 93 years of age. In addition, the length of marriage ranged from 7 months to 67 years with the time since the spouse's stroke varying between one month and 12 years. Consequently, the consistent results among the diverse participants provide support for the dialectical tensions found.

Another strength of this study was the method employed. By employing a qualitative format and open-ended interview questions, I was able to collect rich data based on the disclosure of the participants. At the request of the participants, some interviews were conducted face-to-face while others were conducted over the telephone. This actually contributed to the breadth and depth of this study. During the face-to-face interviews ( $M$ length $=29.78$ minutes $)$, I was able to create a rapport with the interviewee, which increased their comfort level and lead to more in-depth discussion and disclosure. The telephone interviews $(M$ length $=32.51$ minutes $)$ were equally productive because the lack of face-to-face contact increased the feeling of anonymity experienced by the participants; thus, this format increased their willingness to disclose stories and emotions, both positive and negative. Therefore, although the interview technique was 
different, the results were consistent across the methods.

One limitation of this study results from the nature of employing voluntary participants. As previously mentioned, nearly all of the participants appeared to have a very positive attitude toward the situation regarding the stroke survivor and the life adjustments which were required to best benefit the stroke survivor's recovery and ease of functioning. These overly positive responses could have been the result of discussing the situation with someone outside of the situation and not wanting to appear selfish or otherwise negatively to the interviewer. It could be argued that having the stroke survivor present at five of the interviews could have caused the participant to be more reserved regarding discussing her/his emotions and experiences regarding the situation; however, analysis of the transcripts did not show a significant difference in length of the interview when the spouse was present $(M=32.20$ minutes $)$ versus when the spouse was not present $(M=32.27$ minutes $)$, and the same tensions emerged in these discussions. Consequently, the findings from this study could reflect both a social desirability and self-selection bias because all of the participants self-selected themselves to participate and spoke with the interviewer. Thus, there could be other dialectical tensions that spouses of stroke survivors who have a more negative view of their situation may experience but are not represented in this study because such individuals were unwilling to participate.

In addition, another limitation of this study is the possibility that the results could have also been affected by a sample bias due to the inability of some individuals to participate in this study. Participants were recruited from stroke support groups and extended care facilities. Consequently, individuals who have experienced a stroke so 
severe that they cannot attend stroke support groups or were ineligible to stay at an extended care facility (i.e., the stroke survivor goes straight from the hospital to a longterm care home) were not solicited for participation in this study. Thus, spouses of stroke survivors in situations of such severe impairment were not recruited and therefore may experience dialectical tensions not found by this study.

\section{Directions for Future Research}

Ultimately, this study has served as a response to a call for further research from both within and outside the communication studies field, and it offers a first glimpse at the niche area involving how stroke affects marital and family relationships. Future research within this area could take many directions.

One direction for future research involves additional information that emerged during the coding and analysis of the interview transcripts, which suggests that there are key themes experienced by spouses of stroke survivors. Consequently, future research could more closely examine what common themes, such as support and frustration, are experienced by spouses of stroke survivors, what causes the themes, and how they could be managed, thereby enabling the spouses to reduce their stress by addressing the themes.

Another direction for future research could examine what type of strategies would be the most effective in coping with the difficult situations and emotions being the spouse of a stroke survivor produce. By understanding what dialectical tensions stroke survivors and their spouses encounter, methods can be developed to help them recognize dialectical tensions they have not previously dealt with, as well as provide a constructive means of coping, thereby enabling them to reduce their stress and increase their quality of life.

Much like this study continued a line of research regarding how stroke affects 
relationships, a third direction for future research could examine how stroke affects other family members of a stroke survivor. More specifically, future research could examine what dialectical tensions and themes children of stroke survivors experience in order to increase understanding of how stroke affects the family unit because, much like being the spouse of a stroke survivor, being the child of a stroke survivor is a unique situation.

In relation to examining the dialectical tensions and themes experienced by the children of stroke survivors, future research could focus specifically on situations where the child/children are the primary caregiver(s) for the stroke survivor. This situation, although still involving the children of the stroke survivor like the previous suggestion for a future research direction, may produce different dialectical tensions, such as dealing with feelings and communication regarding the role reversal where now the child cares for the parent rather than the parent caring for the child. Also relevant, is the increased responsibility and involvement in the stroke survivor's recovery and issues that may arise due to changes in living arrangements and possible co-habitation.

\section{Conclusion}

This study provided unique insight into the experiences and emotions of spouses of stroke survivors and produced five dialectical tensions unique to their situation: selfpreference - partner-preference, realism - idealism, freedom-constraint, fear-content, and emotional release - emotional reservation. Recognition and better understanding of these dialectical tensions is beneficial to both the spouse and the stroke survivor because it allows them to understand that what they are feeling and experiencing is common among others in their situation. In addition, by creating an understanding of what dialectical tensions both are facing, stroke survivors and their spouses may be better able 
to communicate with one another, thus, reducing stress and increasing the quality of life for both the spouse and the stroke survivor. More research is needed in this area of study because the effects of stroke are unexpected and change the dynamics of the stroke survivors' relationships in an instant; consequently, multiple individuals, particularly family members, are affected by a single event and an increased understanding of how to cope with it could have positive health implications for numerous individuals. 


\section{References}

Alemán, M. W. (2001). Complaining among the elderly: Examining multiple dialectical oppositions to independence in a retirement community. Western Journal of Communication, 65, 89-112.

Baxter, L. A. (1990). Dialectical contradictions in relationship development. Journal of Social and Personal Relationships, 7, 69-88.

Baxter, L. A., \& Erbert, L. A. (1999). Perceptions of dialectical contradictions in turning points of development in heterosexual romantic relationships. Journal of Social and Personal Relationships, 16, 547-569.

Baxter, L. A., \& Montogmery, B. M. (1996). Relating: Dialogues and dialectics. New York: Guilford Press.

Bluvol, A., \& Ford-Gilboe, M. (2004). Hope, health work and quality of life in families of stroke survivors. Journal of Advanced Nursing, 48, 322-332.

Brereton, L. (1997). Preparation for family care-giving: stroke as a paradigm case. Journal of Clinical Nursing, 6, 425-434.

Brereton, L., \& Nolan, M. (2000). 'You do know he's had a stroke, don't you?' Preparation for family care-giving - the neglected dimension. Journal of Clinical Nursing, 9, 498-506.

Brereton, L., \& Nolan, M. (2002). 'Seeking': A key activity for new family carers of stroke survivors. Journal of Clinical Nursing, 11, 22-31.

Galarneau, L. (1993). An interdisciplinary approach to mobility and safety education for caregivers and stroke patients. Rehabilitation Nursing, 18, 395-399.

Harvey, J. H., \& Wenzel, A. (Eds.) (2001). Close romantic relationships: Maintenance 
and enhancement. Mahwah, NJ: Lawrence Erlbaum.

Healthcare braces for boomers; one in six will have multiple chronic illnesses by 2030. (2007, June). H\&HN: Hospitals \& Health Networks, 81, 71.

Impact of stroke. (n.d.). Retrieved November 28, 2006, from American Stroke Association Web site: http://www.strokeassociation.org/presenter.jgtml?identifier=1033.

Lindlof, T. R., \& Taylor, B. C. (2002). Qualitative communication research methods (2nd ed.). Thousand Oaks, CA: Sage Publications, Inc.

Palmer, S., Glass, T. A., Palmer, J. B., Loo, S., \& Wegener, S. T. (2004). Crisis intervention with individuals and their families following stroke: A model for psychosocial service during inpatient rehabilitation. Rehabilitation Psychology, 49, 338-343.

Pawlowski, D. R. (1998). Dialectical tensions in marital partners' accounts of their relationships. Communication Quarterly, 46, 396-412.

Pawlowski, D. R. (2006). Dialectical tensions in families experiencing acute health issues: Stroke survivors' perceptions. In L. H. Turner and R. West, (Eds.), The family communication sourcebook (pp. 469-489). Thousand Oaks, CA: Sage.

Proot, I. M., ter Meulen, R. H. J., Abu-Saad, H. H., \& Crebolder, H. F. J. M. (2007). Supporting stroke patients' autonomy during rehabilitation. Nursing Ethics, 14, 229-241.

Sabourin, T. C., \& Stamp, G. H. (1995). Communication and the experience of dialectical tensions in family life: An examination of abusive and nonabusive families. Communication Monographs, 62, 213-242. 
Santos, M. E., Farrajota, M. L., Castro-Caldas, A., \& De Sousa, L. (1999). Problems of patients with chronic aphasia: Different perspectives of husbands and wives? Brain Injury, 13, 23-29.

Senelick, R., \& Dougherty, K. (2001). Living with stroke: A guide for families ( $\left.{ }^{\text {rd }} \mathrm{ed}.\right)$. Birmingham, AL: HealthSouth Press.

Scott, W. A. (1955). Reliability of content analysis: The case of nominal scale coding. The Public Opinion Quarterly, 19, 321-325.

Strauss, A., \& Corbin, J. (1998). Basics of qualitative research: Techniques and procedures for developing grounded theory ( $2^{\text {nd }}$ ed.). Thousand Oaks, CA: Sage.

Turner, L. H. (2003). Theories of relational communication. In K. M. Galvin and P. J. Cooper, (Eds.), Making connections: Readings in relational communication $\left(^{\text {rd }}\right.$ ed.) (pp. 20-32). Los Angeles: Roxbury.

What are the effects of stroke? (n.d.). Retrieved November 28, 2006, from American Stroke Association Web site: http://www.strokeassociation.org/presenter.jhtml?identifier=1052. 
Appendix A

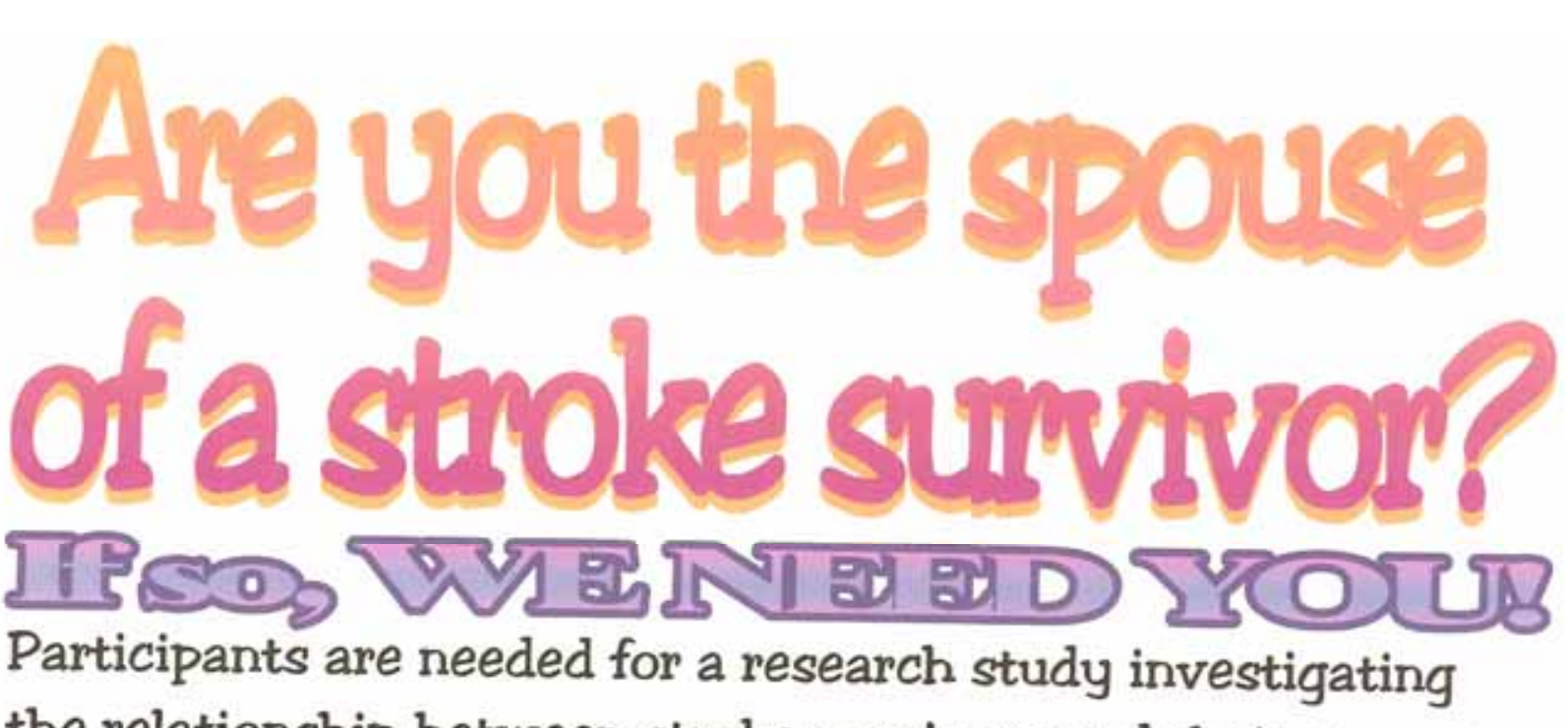
the relationship between stroke survivors and their spouses. Research will include:

- Individuals who are married to a stroke survivor

- Private interviews to discuss your experiences as the spouse of a stroke survivor

The goal of the research is to gain a better understanding of what issues and feelings stroke survivor spouses encounter. Participants will be entered into a drawing for a gift certificate.

FOR MORE INFORMATION, OR IF YOU WOULD LIKE TO PARTICIPATE IN THIS STUDY, PLEASE CONTACT KIMBERLY LEEZER, WVU DEPARTMENT OF COMMUNICATION STUDIES GRADUATE STUDENT, AT:

kleezer@mix.wvu.edu 304-657-9008 304-293-3905

EBERLY COLLEOE OF ARTS AND SCIENCES INSTITUTIONAL REVIEW BOARO FOR HUMAN SUBJECTS APPROVED FOR EXEMPT RESEARCH

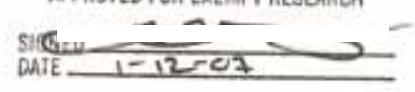




\section{Appendix B}

\section{West VirginiaUniversity}

Department of Communication Studies

Dear Participant:

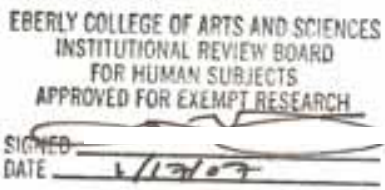

January 10,2007

You are being asked to participate in research conducted as part of a thesis in the Department of Communication Studies at West Virginia University. The purpose of this research is to learn more about the spouses of stroke survivors and their feelings regarding their marital relationship with the stroke survivor. Participation in this research is voluntary and anonymous and simply involves participating in an interview. The amount of time the research takes to complete will be determined by the participant and is merely dependent on how long you wish to talk. You may skip certain questions if you wish and you may stop answering the questions or participating at any time. Your actual performance in this research or your refusal to participate or withdrawal from this research will in no way affect your care with HealthSouth.

If you have any questions or would like more information about the research, please contact:

Kimberly N. Leezer

Graduate Student

Department of Communication Studies

West Virginia University

108 Armstrong Hall, P.O. Box 6293

Morgantown, WV 26506

kleezeramix.wvu.edu

304-293-3905

304-657-9008

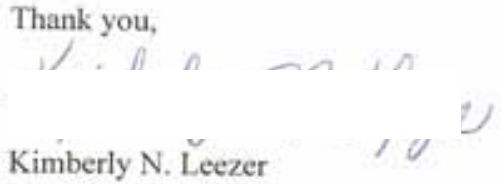


Appendix C

Hello, I'm Kimberly Leezer, a master's student in the Communication Studies Department at WVU. I'm working on my thesis research about how stroke affects communication in marital relationships and the changes and feelings that occur after a spouse's stroke. I am interested in talking with you about how your relationship has changed compared to how it was prior to your spouse's stroke. I am particularly interested in your experiences, feelings, and the emotions you've had to deal with since the incident. Before we begin, I need you to read this letter and formally consent to participate in this research. You will get a copy of this letter to keep in case you have any questions about the project or need to reach me for any reason.

Before we begin, I would like to explain why I am interested in this research. Two of my grandparents experienced stroke. My maternal grandfather experienced two strokes. His first was only recognized because of a vision problem and upon being taken to the Emergency Room was informed that he had had a stroke but with no residual affect. His second stroke was years later and more significant but the only residual effect is paralysis of his right ankle which he continues to receive therapy for and his goal is to recover enough use to begin driving again. My paternal grandmother on the other hand experienced a massive stroke which left her with the inability to speak or swallow and caused her to be bedridden with a feeding tube and in a personal care facility. Her experience is what really caused my interest in this subject because I did not know how to handle the situation, such as what to do when I went to visit her. After speaking with other family members I realized that they also felt the same way - lost and confused about what to do (e.g. Do I tell her about what's going on in my life or will she feel bad because she can't be a part of it, such as getting engaged). Consequently, I realized that there needed to be some type of information available to spouses and families of stroke survivors to give them some idea of what was going on in such a situation and what to expect relationally. Thus, since personal research showed there was not much information currently out there I decided to focus on this topic for my thesis research. To begin, I would like to get some basic information about your relationship.

1.) How long have you been married? How old are you?

2.) How long has it been since the stroke?

3.) How did you feel when you found out about the situation?

4.) What aspect of your life has been affected the most since your spouse's stroke?

5.) What was it like when your spouse came home?

6.) Tell me about a time after the stroke when you realized things would be different.

7.) What is the most difficult part of being the spouse of a stroke survivor? What is the most rewarding part of being the spouse of a stroke survivor? 
8.) How has the stroke affected your relationship?

9.) How do you communicate with your spouse now compared to prior to the stroke?

10.) Are the subjects you discuss different from those discussed prior to the stroke (i.e., subjects not discussed now which were discussed before and vise-versa)? What are some differences?

11.) Do you think you and your spouse have similar thoughts about the current situation? How might they be different?

12.) Is there anything I have not asked you about you would like to add? Or what advice would you give someone who is in a similar situation but at the beginning of this long journey? 


\section{Notes}

${ }^{1}$ One participant was not formally married to her partner, but the relationship was serious; she had been with the stroke survivor both prior to the stroke and currently; they had known one another for 30 years; and they had been a serious couple for 2 years.

${ }^{2}$ All names have been changed to protect the identity of the participants and their spouses. 
Table 1

Participant Demographic Information and Interview Description

\begin{tabular}{cllllcccc}
\hline Interview & Sex & Age & $\begin{array}{c}\text { Face-to-face } \\
\text { / phone }\end{array}$ & $\begin{array}{c}\text { Spouse present } / \\
\text { Spouse NOT present }\end{array}$ & $\begin{array}{c}\text { Years } \\
\text { married }\end{array}$ & $\begin{array}{c}\text { Months } \\
\text { since stroke }\end{array}$ & $\begin{array}{c}\text { Length of Interview } \\
\text { (minutes) }\end{array}$ & Pages \\
\hline 1 & Male & 58 & Face-to-face Spouse present & 12 & 24 & 25 & 9 \\
2 & Female & & Face-to-face Spouse present & 17 & 3 & 14 & 5.5 \\
3 & Female & 61 & Face-to-face & Spouse NOT present & 16 & 12 & 13 & 4.5 \\
4 & Female & 42 & Face-to-face & Spouse NOT present & & 1 & 44 & 15 \\
5 & Male & 21 & Face-to-face & Spouse NOT present & 1.3 & 2 & 30 & 5 \\
6 & Female & 93 & Face-to-face & Spouse present & 67 & 5 & 21 & 5.5 \\
7 & Female & 76 & Face-to-face & Spouse present & 58 & 12 & 31 & 9.5 \\
8 & Male & 42 & Face-to-face & Spouse present & 7 & 1 & 60 & 3 \\
9 & Female & 61 & Face-to-face & Spouse NOT present & 40 & 2 & 30 & 3 \\
10 & Male & 83 & Phone & Spouse NOT present & 58 & 48 & 27 & 6.5 \\
11 & Female & 72 & Phone & Spouse NOT present & 25 & 144 & 22 & 7 \\
12 & Male & 74 & Phone & Spouse NOT present & 0.58 & 84 & 24 & 6 \\
13 & Female & 59 & Phone & Spouse NOT present & 39 & 41 & 45 & 8 \\
14 & Female & 74 & Phone & Spouse NOT present & 48 & 84 & 46 & 8 \\
15 & Male & 65 & Phone & Spouse NOT present & 40 & 60 & 36 & 9 \\
16 & Female & 40 & Phone & Spouse NOT present & 17 & 18 & 38 & 9.5 \\
\hline
\end{tabular}

